\title{
Continuing professional development: pedagogical practices of interprofessional simulation in health care
}

Sofia Nyström, J ohanna Gustavsson, Samuel Edelbring, Håkan Hult and Madeleine Abrandt Dahlgren

The self-archived version of this journal article is available at Linköping University Electronic Press:

http:/ / urn.kb.se/ resolve?urn=urn:nbn:se:liu:diva-138028

N.B.: When citing this work, cite the original publication.

This is an electronic version of an article published in:

Nyström, S., Gustavsson, J., Edelbring, S., Hult, H., Abrandt Dahlgren, M., (2017), Continuing professional development:: pedagogical practices of interprofessional simulation in health care, Studies in Continuing Education. https:/ / dx.doi.org/ 10.1080/ 0158037X.2017.1333981

Original publication available at:

https:// dx.doi.org/ 10.1080/0158037X.2017.1333981

Copyright: Taylor \& Francis (Routledge): SSH Titles

http://www.routledge.com/ 


\section{Continuing professional development: Pedagogical practices of interprofessional simulation in health care}

Sofia Nyström ${ }^{1}$, Johanna Dahlberg ${ }^{2}$, Samuel Edelbring ${ }^{3}$, Håkan Hult ${ }^{4}$ and Madeleine Abrandt Dahlgren $^{5}$

1

${ }^{1}$ Corresponding author. Department of Behavioural Sciences and Learning, Linköping

University, Linköping, Sweden. Sofia.nystrom@liu.se +4613282095

2 Department of Clinical and Experimental Medicine, Linköping University, Linköping, Sweden. Johanna.dahlberg@liu.se +4613286876

3

3 Department of Medical and Health Sciences, Linköping University, Linköping, Sweden.

Department of Learning, Informatics, Management and Ethics, Karolinska Institutet,

Stockholm, Sweden. Samuel.edelbring@liu.se +4613282614

4

4 Department of Medical and Health Sciences, Linköping University, Linköping, Sweden.

Hakan.hult@liu.se

${ }^{5}$ Department of Medical and Health Sciences, Linköping University, Linköping, Sweden. Madeleine.abrandt.dahlgren@liu.se +46 13282135

\section{Abstract}

The increasing complexity of health care practice makes continuing professional development (CPD) essential for health care professionals. Simulation-based training is a CPD activity that is often applied to improve interprofessional collaboration and the quality of care. The aim of this study is to explore simulation as a pedagogical practice for the CPD of health care professionals. Specifically, the study focuses on how a professional development activity, the simulation, is enacted to support interprofessional collaboration and learning. A practice theory perspective is used as the theoretical framework. In this, the professional practice is conceptualised as being embodied, relational and situated in sociomaterial arrangements. Ten introduction and reflection sessions following interprofessional full-scale manikin-based simulations with professionals were videorecorded. The recordings were analysed following a stepwise qualitative collaborative approach developed for the purpose. The key findings suggest that the professional competence activity is enacted and interconnected with and governed by historical traditions 
of institutional teaching practices as well as simulation practices. Despite the intentions of team and interprofessional training, the institutional teaching and simulation practices constrain and hinder the intended outcomes of professional development in interprofessional collaboration.

Keywords: continuing professional development, healthcare, interprofessional collaboration, simulation, practice theory, qualitative video analysis.

\section{Introduction}

The changes and complexity of working life require critical exploration and recontextualization of professional learning and continuing professional development (CPD), especially in health care (e.g. Bradbury, Kilminster, O’Rourke \& Zukas, 2015; Fox \& Reeves, 2015). Furthermore, in the last few decades the use of CPD has changed from acts in which professionals are engaged and directed by their own needs, to a "systematised and codified set of activities" needed for professionals to practice their profession (Boud \& Hager, 2012, p. 17). This risks moving attention from the intended outcome of CPD to the activity itself. The focus on the activity makes professional learning individualised and acquisition-focused (Reich, Rooney \& Boud, 2015). At the same time, the CPD activities are increasingly identified and regulated by professional bodies or employing organisations as part of a continuing professional education (CPE) framework in which standards, competences and capabilities are identified. Reich, Rooney and Boud (2015) argue that these frameworks separate professional learning from its practice in assuming learning to be measurable and specifiable as an entity in itself.

One such CPE framework is the core competencies for interprofessional practice in health care, as defined by the Interprofessional Education Collaborative Expert Panel (IPEC, 2011). The rationale of interprofessional continuing professional learning is to reduce medical errors and increase the efficiency and capacity of the health care workforce. Health professionals need to learn from, with and about each other in order to improve the safety and quality of health care (IPEC, 2011) in order to meet future health care demands (WHO, 2010). However, taking on the challenge of working as an interprofessional team requires rethinking of professional training. The issue of how to prepare professionals for interprofessional working and learning for future health care has become increasingly important for professional educators. Instead of professional education traditionally taking place uniprofessionally, the need to commingle different professional-specific modes of knowing and reasoning has been pointed out as necessary (Guile, 2014; Fox \& Reeves, 2015). Research has shown that interprofessional collaboration is intertwined with interprofessional learning and how the workplace is organised (Collin, Valleala, Herraanen \& Paloniemi, 2012). It is thus not enough to arrange a series of activities. Moreover, Guile (2014) suggests a need for a recontextualization of the content, pedagogy, workplace and finally, the learner in relation to professional formation (p. 134).

The present study takes its starting point in one example where such a recontexualisation is applied in CPD for training in interprofessional collaboration, i.e. the use of simulation-based training. Recent studies on the training of interprofessional collaboration skills indicate that interprofessional simulation improves role clarification and promotes problem-solving skills (Titzer et al., 2012). However, there are reasons to scrutinize 
simulation as a pedagogical practice for CPD. Taking a pedagogical perspective on the literature of simulation, Rooney et al. (2015) identify three focal themes of interest concerning 1) the fidelity of the simulation, 2) the linking of simulation to outcomes in practice, and 3) pedagogical underpinnings. The last theme, pedagogical consideration and underpinnings, which is especially relevant for this paper, focuses on the teaching practice and learning process as a relationship between learning and technology. There is a call for more research on how simulation, in the form of activities for competence development, is organised, and there is also a need to explore and expand the conceptualisation of simulationbased training (Rooney et al., 2015). Furthermore, researchers have called for more theorised, process-oriented analysis of current simulation practice (e.g. Berragan, 2011). Reich, Rooney and Boud (2015) argue for an alternative, continuing, and professional learning framework that is relational and emergent. Therefore, this paper takes a practice-oriented perspective on professional learning (Hager et al., 2012). Practice-oriented perspectives recognise the professional practice of health care as being embodied, relational and situated in sociomaterial relations, thereby promoting learning as an integral part of practice (Hager et al., 2012; Green \& Hopwood, 2014).

Simulation is usually a technology-enhanced strategy for learning, and it has spread across various areas of professional learning, and is common in health care training. Simulation has thereby moved beyond the historical use of being a tool for learning discrete skills, and is now used as a means of providing training in complex professional practices. Simulation is also increasingly being used for the teaching of cognitive, psychomotor and affective skills to individuals and teams (Motola et al., 2013). A technically advanced manikin enables full-scale simulations using acute scenarios to practice team collaboration and interactions. Simulation training is often viewed as a self-evident and normative teaching method. Researchers on the other hand, argue that there has been little critical discussion of how to work with simulation, and therefore, the pedagogical considerations and impact of such training are still under-researched (Gough et al., 2012; Rooney et al., 2015).

The sequence or model for simulation training that is suggested in the literature (e.g. Dieckmann, 2009) and used in practice is basically structured according to three general phases that are normally expected to follow a certain sequence. The first phase, the briefing, provides information on the technical equipment in use and the scenario that is about to be simulated. The second phase, the actual simulation, is where participants come together to enact the scenario in practice as if it was an authentic patient case. In the third phase, the debriefing, participants' emotional reactions, actions and interactions in the scenario are brought up as topics for reflection. Debriefing can be seen as a social practice and as critical for professional learning, serving various purposes such as promoting reflection (Dieckmann, 2009; Reamer et al., 2011). Fanning and Gaba (2007) state that debriefing is one way to bridge the gap between experiencing an event and learning from it. The literature presents a multitude of models of debriefing to meet different learning outcomes (Jefferis, 2013). A general feature of the models is that they prescribe a defined sequence of phases that the debriefing should follow (Rudolph et al., 2006). Firstly, the participants' actions during the simulation should be described in a conceptual phase. Secondly, their experience and performance should be analysed, and thirdly, the discussion should consider how the learning could be applied. The instructors' ways of conducting the debriefing, and the probing questions to the participants, are seen as crucial (Dismukes, Gaba \& Howard, 2006). Dieckmann et al. (2012) elaborate on the instructor role by showing that dynamics of interaction vary with different instructors, suggesting that instructors adopt different styles, influencing the process and outcome of the debriefing. Husebø et al. (2013) showed that the instructors' pose more descriptive than analytic questions. There is a need, the authors argue, 
for research on debriefing to develop a more analytical framework for probing questions in order to facilitate deeper reflection.

Rooney et al., (2015) argue for including the material arrangements in the analysis, i.e. the simulator and the set-up for the simulation. From a practice theory perspective, social and material arrangements are seen as active components of the enacted practice, and therefore also potentially influence the learning outcome in ways that go beyond abstract outcome measures and experimental comparisons. The feasibility of such perspectives for simulation can be illustrated by previous studies by Nyström et al. (2016a, 2016b). The study on students' interprofessional collaboration in the simulation showed that interprofessional knowings and enactments emerged as a fluid movement between bodily positioning in and out of synchrony (Nyström et al., 2016a). When in sync, the students performed and enacted interprofessional collaboration where sayings, doings and bodily movements were connected in a chain of actions. In their studies on debriefing, Nyström et al. (2016b) identified two distinct patterns of enacting debriefing, one protocol-based and one more loosely structured collegial conversation. However, non of the structures ensured that interprofessional collaboration emerged as a salient topic for reflection.

In the present study, we continue to apply a practice theory perspective on professional learning and practice (Kemmis, 2009; Schatzki, 2002, 2010). A focus on the social and material arrangements as relational can shed light on how and why certain activities become practically intelligible, i.e. more or less likely to happen in the unfolding practice (Schatzki, 2002). The CPD activity is therefore viewed as an organised set of actions embedded in a practice. This perspective emphasises material set-ups as dynamic and integrated with human activities in ways that act on practice. Furthermore, the emphasis is not on singular things or technologies but on relationships between material arrangements and human actions and what these produce (Fenwick \& Abrandt Dahlgren 2015).

A practice presupposes a certain arrangement of human actions expressed through language, actions, and relations between individuals - 'sayings,' 'doings,' (Schatzki 2002) and 'relatings' (Kemmis, 2009). The sayings concern different ways of thinking and discussing what a professional practice is and means. The doings concern the different types of activities and work performed by the professionals and the way these doings influence others in the same practice. In addition, every practice has its own relatings: certain arrangements of people, roles, and relations (Kemmis \& Grootenboer, 2008).

The activities that make up a practice are organised and linked by understandings, rules, and normative teleologies (Schatzki, 2010). The simulation practice therefore has principles and aims that regulate what kind of actions can be carried out and what is seen as acceptable.

The aim of the study is to explore simulation as a pedagogical practice for the CPD of health care professionals. Specifically, the study seeks to answer the research questions of a) how the competence development activity is introduced, and b) how the reflection following the simulation is enacted to support interprofessional collaboration and learning.

\section{Method}

This paper draws on empirical data gathered through video-recordings and observational field notes on the practices of introduction before simulation activities and subsequent reflection as a professional development activity in health care. 


\section{The contexts of the study}

The contexts in this study were two simulation centres in Sweden (site 1 and site 2) where health professionals participated in a one-day activity (comprising 4-8 hours) of simulation training. The stated aim of the simulation-based training was to train together to improve teamwork and interprofessional collaboration. All scenarios included in the simulation were variations of an acute emergency or deteriorating condition of the patient.

\section{Participants and data collection}

The introduction, the simulations as well as the reflections were video-recorded in their naturalistic setting (i.e. not designed by the researchers). The data are based on observations from ten introductions and reflection sessions from the two different sites. These settings varied in their layout as well as the time allocated for the respective activities. In addition, we also studied the documents that were sent out to the CPD participants beforehand.

Altogether, 18 professionals - 14 females and four males - participated in the sessions, either as active participants or as observers in the simulation scenarios. The participants were grouped into interprofessional teams based on their professional background. At site 1, seven sessions were video-recorded with medical doctors and nurses (in total 13 participants). At site 2, three sessions were video-recorded with anaesthetist, nurses, medical doctors, and midwives (in total five participants). The professionals had varying experience of simulation exercises, from no previous participation to participation on a few occasions. Altogether, six experienced instructors participated - one male and five females - with different health professional backgrounds.

\section{Data analysis}

Data were analysed collaboratively by the authors, who had different backgrounds in healthcare work (such as physiotherapist, biomedical laboratory scientist) and in medical education as well as in education. The empirical data in this paper is based on 16 hours of video-recordings. A purposeful approach to collaborative data analysis, comprising a layered process in three phases of activities, was developed and utilised by a group of five researchers. The process was inspired by constant comparative analysis as described by Boeije (2002) and video analysis as described by Heath, Hindmarsh, and Luff (2010). Table 1 illustrates the different phases of the collaborative analysis, which was developed for the purpose of this study.

As a first phase, individual field notes were taken while observing the first videorecording together. The theoretical perspective directed the analytical attention towards how the nexus of actions hanged together as relationships between material entities including both human and non-human actors, such as the arrangements of professionals' bodies, the environments, and protocols in use. The individual field notes were cross-checked, compared and finally merged and transcribed into a joint, preliminary description of the enacted interprofessional collaboration as a relationship between bodily movements and arrangements. This first phase made it possible to obtain a shared understanding, as well as to articulate the focus for the second phase, in which comparisons between different videorecordings of the same scenario were made. The second phase allowed us to identify the preliminary findings regarding how the introduction and the reflection were enacted in different video-recordings. In the third phase, comparisons were made between video- 
recordings of different scenarios, with the purpose of enlarging and refining the provisional interpretation against all data. The third phase resulted in the identification of different enactments of introduction and reflection related to sociomaterial arrangements.

Table 1: Three phases of collaborative analysis of video-recorded simulation sessions

\begin{tabular}{|c|c|c|c|c|}
\hline $\begin{array}{l}\text { Phase 1-3 of the } \\
\text { analysis }\end{array}$ & Purpose & Analysis activities & Questions & Results \\
\hline $\begin{array}{l}\text { 1. Comparison of } \\
\text { multiple } \\
\text { perspectives } \\
\text { within a single } \\
\text { video-recording }\end{array}$ & $\begin{array}{l}\text { Developing } \\
\text { collectively } \\
\text { enriched and } \\
\text { shared } \\
\text { understanding of } \\
\text { the sequence of } \\
\text { activities }\end{array}$ & $\begin{array}{l}\text { Merging individual } \\
\text { field notes, reaching } \\
\text { consensus on } \\
\text { interpretations of } \\
\text { fragments }\end{array}$ & $\begin{array}{l}\text { How is the } \\
\text { introduction of } \\
\text { interprofessional } \\
\text { collaboration } \\
\text { enacted? } \\
\text { How are different } \\
\text { professional } \\
\text { knowings made } \\
\text { relevant in the } \\
\text { reflection after the } \\
\text { sessions? }\end{array}$ & $\begin{array}{l}\text { Focus and process } \\
\text { for phase } 2 \\
\text { determined } \\
\text { Structural features } \\
\text { for comparing } \\
\text { video recordings } \\
\text { formulated } \\
\text { (openings, } \\
\text { interaction, } \\
\text { closings) }\end{array}$ \\
\hline $\begin{array}{l}\text { 2. Comparison } \\
\text { between video } \\
\text { recordings of } \\
\text { different } \\
\text { scenarios }\end{array}$ & $\begin{array}{l}\text { Developing a } \\
\text { shared } \\
\text { understanding of } \\
\text { the patterns } \\
\text { across the data }\end{array}$ & $\begin{array}{l}\text { Comparing openings, } \\
\text { interconnections } \\
\text { between human and } \\
\text { non-human actors, } \\
\text { and closings. }\end{array}$ & $\begin{array}{l}\text { How is the sequence } \\
\text { of activities in the } \\
\text { introduction enacted? } \\
\text { How is the reflection } \\
\text { on interprofessional } \\
\text { collaboration enacted } \\
\text { across scenarios? }\end{array}$ & $\begin{array}{l}\text { Transcripts of } \\
\text { selected segments. } \\
\text { Provisional } \\
\text { interpretations as a } \\
\text { focus for phase } 3\end{array}$ \\
\hline $\begin{array}{l}\text { 3. Theorising and } \\
\text { comparing data } \\
\text { across sites }\end{array}$ & $\begin{array}{l}\text { Enlarging and } \\
\text { enriching the } \\
\text { basis for } \\
\text { interpretation. } \\
\text { Identifying } \\
\text { variation }\end{array}$ & $\begin{array}{l}\text { Refining provisional } \\
\text { interpretations } \\
\text { against wider data }\end{array}$ & $\begin{array}{l}\text { How are socio- } \\
\text { material arrangements } \\
\text { related to sayings and } \\
\text { doings in the } \\
\text { introduction and } \\
\text { reflection across } \\
\text { sites? }\end{array}$ & $\begin{array}{l}\text { Relational patterns } \\
\text { across all data }\end{array}$ \\
\hline
\end{tabular}

\section{Findings}

\section{Doing briefing: Setting the scene for learning}

This section focuses on how the simulation training is introduced to the participants. The findings suggest that the different institutional traditions that form the general and practical understanding of teaching and learning also made different pedagogical practices intelligible at the two studied sites. At one of the sites, the way of setting the scene for learning in the briefing of the scenario can be characterised as a practice where experts were acting as role models, while literally demonstrating the anticipated enactment of the scenario. At the other site, the way of setting the scene for learning and briefing of the scenario, could be characterised as collegial conversation, where participants' individual learning objectives for the day were discussed and listed. The analysis shows that the different ways of introducing the training produce different conditions for the learners’ participation. 


\section{Doing briefing 1: Instructors as expert role models}

At site 1, the invitation and documents were sent out to participants prior to the training to set the scene for learning in simulation. The information or "pre-briefing" of the simulation training, emphasised simulation as being an evidence- and research based activity for professional learning. To support this notion, the invitation also contained a research article on simulation and crisis resource management as a preparatory reading for the participants. The invitation and documents are interpreted as sayings that convey the institutions' traditionally high profile in research.

In the expert role-modelling practice at site 1 , the learning objectives were decided prior to the training, regardless of group of participants, and presented by the instructors to the participants in a slideshow. The slideshow acted as a guide for what topics should be considered central domains of learning in the simulation training. The material set-up of the room prefigured the positioning of instructors and the participants in the session as a traditional classroom, with the participants positioned in a row in front of the instructors. This kind of configuration of instructors and participants also prefigured the expected pattern and direction of communication as instructors as lecturers.

The emphasis on expert role-modelling can also be illustrated by the time allocated for the preparation of the simulation exercise. The subsequent doings and relatings of the instructor at the beginning of the day and after each scenario were characterised by demonstration and showcasing of the anticipated behaviour of the participants. The pedagogical practice in this phase of the simulation training can be interpreted as experts acting as role models for the participants as they demonstrate the correct professional procedures and how the ideal procedures of simulation should be carried out prior to the start of the simulation exercise. The role-modelling is enacted through the way instructors give lectures on how to implement the ATLS protocol (acute trauma life support). As the field note below illustrates, the practice of communication within the team is also guided by an expert hierarchical model of leadership, conveyed by the teacher's lecture.
It is in the beginning of the day and the two instructors have just gone through the planning of the day. Learning objectives have been conveyed to the participants, together with instructions on how to think about the simulations and the debriefings. One of the instructors stands up and starts, "Well, there are some small issues which I hope that we can agree upon before we continue, and if not, then I hope you can tell me why. Picture this: there is an emergency and you have to choose an action. This process works best if you have an individual, preferably the person with the highest medical competence at the scene, who acts as a leader and takes responsibility for organising the work. It is no coincidence that we and everybody else work in this way". Then the instructor continues to talk about why leadership and communication are important and how the individual can use the resources of the whole team by emphasising safe communication and by demonstrating professional behaviour. (Site 1- introduction 4)

After the demonstration, the participants were requested to practice the procedures themselves in teams of two. If the instructor was not satisfied with the participants' doings they were asked to repeat the procedure. The expert role-modelling pedagogical practice was characterised a hierarchical relationship between instructor and participant. The following field note exemplifies how the instructor is modelling the behaviour of the participants as a preparation for the simulation exercise.

The simulation room is set up as a hospital room and the patient (manikin) is lying in a bed. The instructor is standing by the head of the patient and the participants stand around the bedside. The technical briefing has started. The instructor is going through the ATLS protocol and says, "When you look at the lungs [roles down the blanket that covers the patient so the chest is shown] you 
can feel, if you feel here [holds her wrist over the patient's mouth] you can feel how she breathes. Feel it." Each one of the participants follows the instructor's directive. The instructor continues, "If you cover her mouth then she will suffocate. When you put on the oxygen mask, you have to do it properly." The instructor then goes on to explain how to put on the oxygen mask and where all the equipment can be found. The instructor emphasises that participants do not need to remember, because she will be in the room so they can always ask her. She continues, "We have to see that the patient is breathing. Where should you put the stethoscope so you can hear her breathe?” One of the participant answers and the technical briefing continues. (Site 1-technical introduction)

\title{
Doing briefing 2: Instructors and participants in collegial conversation
}

The pre-briefing at site 2, as expressed in the documents sent out to the participants prior to the training, emphasised simulation as a participatory activity. The information materials and invitation to the simulation day encouraged the participants to participate in the exercise and to mingle and to learn together.

The pedagogical practice in site 2 was enacted as a primus inter pares model, i.e. a collegial conversation where the relationship between the instructors and the participants was equal, but the instructors were given the mandate to lead and instruct, in a collegial model of teaching. The collegial model of teaching was also prefigured by the sociomaterial set-up of the room. The positionings of participants and instructors at a round table, facing each other, prefigured a teaching practice as a seminar to which participants contributed in a collegial conversation.

The collegial pedagogical practice was expressed through instructors' sayings and acknowledgement of the professional knowledge of the participants. In the field note below, this is reflected in how the instructor comments on the material set-up of the room, acknowledging that the participants are familiar with this kind of material arrangement in their everyday work.

\begin{abstract}
The simulation room is set up as an emergency delivery room and a baby [a baby size manikin] is lying on a table and the participants and the three instructors are standing around. The technical briefing has started. The instructor points to the table and says, "The table is fully equipped as we are used to. I guess and assume that we are all well aware of how it works and what you can find there. Therefore, I won't go through it. If you want to search for someone, you use the phone and press Int1. Then we have the manikin [unfolds the blanket that was on top of the manikin], and it breathes as you can see and you can hear the heartbeat. You can all listen.” All the participants step forward and two stethoscopes are passed around so they all can take turns to listen. (Site 2technical introduction)
\end{abstract}

The collegial conversation was also discernible in the way the learning objectives were formulated and how they operated. The way the instructors introduced the simulation exercise was characterised by fluidity and relational to personal learning objectives of the participants, as well as the team enactments in the scenarios, emerging over the course of the day. After each scenario, the instructor encouraged the participants to revisit the learning goals in order to identify the learning that occurred and to identify further learning needs for the coming scenario. The findings show that the listing of the common learning goals for the day linked the individual participants' learning and training to the learning of the other team members learning. The following field note is an example of this:

The instructor starts the briefing before the second scenario by saying: "We will now start the second scenario. Before the first simulation we gave you a learning objective that focused on communication. On the basis of what we have been talking about now, what learning objective would you like to state for this scenario? Spontaneous, anyone?” One of the midwives starts by 
saying "Well, communication. If I tell you [points to one of the participants] 'Call the anaesthetist' and then you answer 'I have called the anaesthetist'”. The instructor nods and says, “Closed-loops”. Another instructor writes 'closed-loops' on a flipchart. The discussion around the table continues but they end up by posing one learning objective for the team to focus on in the next scenario. (Briefing 2-site 2)

\section{Doing debriefing: Reflecting on what was learned}

So far, we have shown that the practices of introducing the simulation exercise varied across the two sites, in our interpretation as a function of different traditions and general and practical understandings of teaching and learning. Our findings show that the practices of facilitating reflection after the simulation at the two sites were more characterised by similarities, sharing a common focus on relatings between individual participants, and the individual doings and sayings in relation to the simulated patient and the medical equipment. Another similarity between the two sites was that the performance of the team was scarcely commented on.

\section{Participants' focus}

The focus on individual doings in relation and response to other participants and the sequence of events in the simulation was the characteristic and most common way of reflecting upon what happened in the simulation. Participants were instructed to think about and describe individually things they did well and individual things they could improve, based on what happened during the simulation. The instructions can be interpreted as the rules (Schatzki, 2002) that compose and influence the practice of debriefing, directing the participants to perform certain actions and bring up certain topics for discussion.

It is the third reflection of the day and they have just started. The instructors turn to the acting physicians and ask, "How was it?” Kristina starts, "Well...” and she laughs. The instructor: "You decided who was going to be the acting leader?” Kristina nods and says, "Yes, it was me. Well we did the ATLS. You [turns to Marcus] started quickly with ECG. I remembered to call Ward four this time. Well... I almost think that the hardest part is to remember the oral report that we got first. Remember it so you can report later on.” The instructor nods and says, "Yes, it is hard to remember but it is good to practice”. (Debriefing 2-site 1)

\section{Focus on the patient and the medical equipment}

The second issue that emerged as a focus for the reflections concerned the patient/manikin. Here, the sayings emphasised the medical condition, how it could be treated and what would constitute a correct professional behaviour. Reflecting upon the medical status of the patient and the appropriate treatment and behaviour can be seen as teleoaffective structures at play (Schatzki, 2002) in the reflecting practice. A normative dimension of praising or correcting certain professional behaviour and performances as well as medical procedures guided the reflection at this stage. These sayings also included aspects of shared knowing-in-practice (Gherardi, 2009) based on professional experience and what kind of actions would be preferable and functional in a certain situation. One of the instructors shared his professional experience and asked:

Is there anyone who is wondering about the condition of the patient? Is it crystal clear? [None of the participants' answers]. Well, the patient had XX [refers to the condition of the patient] ./../Does everybody know how to examine it? When I was a student I thought that the patient should do this [waves with his arms] but what you do is to examine whether the patient can hold 
the hands like this [bends his wrists and demonstrates] /.../ It is very important that you can understand if the patient has this condition. (Instructor 1-Site 1).

\section{Focus on team performance}

The last issue raised in the reflection focused on the team performance. This occurs when the descriptive focus on individual actions happening in the sequence of events in the simulation is shifted towards a team-directed analysis. In team-directed analysis, the social and material arrangements of the simulation such as communication, taking action and bodily positionings are the main focus. When team performance is emphasised over the individual actions, knowings and leadership emerge as relational and embodied, as illustrated below. First, we show how team performance emerged as communication. The collaboration in the team is increased if individual sayings (or the absence of sayings) are responded to by the others in the team.

The instructor addresses the whole team and says, "Is there something else during the scenario that you, who worked in the team, want to point out that Stina [midwife] did well?"/.../ The female medical doctor says, "You had a lot of suggestions". The midwife looks at the medical doctor and then the instructor and says, "I think it is hard with so many suggestions." The instructor looks a bit surprised and says, "Do you think it is hard?” The midwife continues "Well, it is like we should do this and we should do that. I think that you should give orders so it gets done. The instructor nods and says, "If you stand and work and then you realise something would be good to do, what do you do?” The nurse says; "Communicate! /...” The instructor confirms but says, "OK, if Stina gives a suggestion that you do not think that Kerstin heard, and the suggestion is hanging in the air, what can you do?" The nurse says, "Listen, and ask if we should do that." "Yes, but if you ask Kerstin 'Should we give blood?'” the instructor continues. The nurse nods and looks at the medical doctor and says, "Yes.” The instructor summarises, "You [ a midwife] have given a suggestion, that you [a nurse] have heard but you can see that Kerstin does not react, and then you ask Kerstin, who then again will hear the suggestion and can take an active decision about it.” (Debriefing 2-Site 2)

Second, team performance also emerges as a common responsibility for taking action. The reflections concern awareness of one's own professional knowledge and skill in relation to the other members. The sayings in the debriefing emphasise a need for speaking up, standing up, noticing when the profession's specific skills and knowledge are needed, and to adopting leadership. Here the debriefing is emphasising the relatings between the professionals' actions in the team.

The reflection has been going on for a while and one of the physicians has been reflecting upon the scenario and his leadership. The instructor turns to the others in the team and asks: "You, who were observers, what are your thoughts?” One of the physicians answers: "I think that when you came in you explained a lot and told everyone what you thought and what you were doing. If I had been you [points to the acting nurses] I would have had a clear picture of what was going on and what needed to be done. You were clear and coherent. I'm almost jealous of how you did it.” The acting physician answers "Well I think that you should do that; speak up and say what you think. In the last simulation, I talked so much that no one got a chance to speak, and that is not good. It is a balance. If you talk too much the others can think it is an order and become confused, but you also need to speak up and show what you think.” The instructor turns to the acting nurses: "You, who were in the room, what did you think about Roger as the leader?" One of the nurses: "Well I thought it was good when you came in. I'm not sure that I left a good report but I think that you thought the same as we thought from the start.” The observing physician continues "You [turns to the two physicians that were in the simulation] were a bit unclear on whether this was a patient for X ward or not. You took time to discuss it and that was very good”. The debriefing is coming to an end and the instructor turns to the acting nurses and comments: "I just wanted to say that you, nurses, are sometime a bit too careful so you should be more positive, raise your voice 
and speak up so everyone can hear, especially if there are many people in the team.” The observing physician "Well, I thought that you did it well and you came with the oxygen." (Debriefing 3- Site 1)

Last, the issue of team also emerged through how bodily positionings were arranged in the enactment of collaboration in the team, for example whose hands were working with what and how to anticipate the team's actions. The movements of the professional team members were connected in a fluid chain of actions. The activities of the chain of different activities such as noticing a sign indicating a deterioration of the patient's condition (auditory or visual), which was followed by enactment of leadership through taking action, or responding through attuning to the action of others. The instructor facilitated the attunement to the priorities made by the team, and challenged reflection concerning the anticipation of the next action in the way the material arrangements were related to and how responsibilities for different actions were distributed in the team. The reflection and connections made between individual and team performance did not increase over the day.

\begin{abstract}
The instructor turns to one of the midwives and asks, "Did you feel like you were redundant?" The midwife thinks and says, "Well in the end maybe. The instructor: "Did you feel there were enough people around the table?” The midwife: "Yes, I did”. The instructor continues: "I thought you may have thought that since you decided to go and get blood yourself." The midwife: "I think that Kerstin (the medical doctor) asked me and I thought, yes I could do that since I wasn't doing anything at the time. But maybe I should have stayed because I think a lot happened when I was away, with drugs, so it might have been better if somebody else had done it.” The instructor: "How long would it take if you ran off to get blood? " [The comment relates to the professional practice and their everyday work]. The midwife thinks for a while and says, "It takes time of course, longer than it took here.” Another midwife comments: "There and back it is at least five minutes". The instructor addresses the whole group and says, "When you have a child as sick as this, you will need all the resources that you can get, and sometimes even more, so if someone else could do this kind of task it is preferable. ” (Debriefing 1-Site 2)
\end{abstract}

\title{
Discussion
}

The increased pressure for CPD for healthcare professionals is suggested to be necessary due to the changes in the professional practice (Bradbury, O’Rurke \& Zukas, 2015) and is actualised in different frameworks for competence development and training (Reich, Rooney \& Boud, 2015). This paper explores how healthcare professionals further develop core competencies for an interprofessional practice (IPEC, 2011) by the use of simulation training. The aim of the study is to explore simulation as a pedagogical practice for the CPD of health care professionals. Specifically, the study seeks to answer the research questions of a) how the competence development activity is introduced, and b) how the reflection following the simulation is enacted to support interprofessional collaboration and learning.

In line with previous research (e.g. Reich, Rooney \& Boud, 2015), the findings in this paper show a focus on the competence development activity (the simulation) rather than the desired outcome. The CPD activity is designed for health professionals to practice interprofessional teamwork. However, the findings show a reinforcement of keeping different types of professional knowledge separated, expressed as medical knowings and professional behaviour. With the use of a practice theory it is possible to understand how the CPD is enacted and interconnected with and governed by historical traditions of teaching practices as well as simulation practices. These practices are also enacted in relationships between the instructor, participants, material objects and the set-up of the simulation setting. 
One of the key findings is that there are great differences in the ways of introducing the training in conducting briefing as expert role-modelling and condicting briefing as collegial conversation produced by different teaching practices. The conditions appear to be influenced by different institutional traditions and values of teaching practices, which emerge in instructors' ways of arranging and performing the introduction, and which can support or constrain (interprofessional) learning. The findings show that the introduction starts with written information sent to the participants beforehand. Previous research (e.g. Dieckmann, 2009; McDermott, 2016) argues for the importance of a pre-briefing since it prepares the professionals for the simulation as well as for a reflective practice in the debriefing. In this study, we show how the 'pre-briefing', i.e. introduction practices, are enacted by the instructor and the participants following two distinctive patterns of teaching practices. These practices are built up by different relationships between sayings, doings and relatings in the simulation. These differences give the instructor and the professionals, i.e. as learners, different opportunities to relate to each other and to the activity itself. The expert rolemodelling practice is enacted as a hierarchical relationship between the instructors and the professionals, positioning the participants as learners and the instructor as an expert. The collegial teaching practice, on the other hand, is enacted in a primus inter pares model of teaching, a relationship where the instructors are given the mandate to lead the session, but in this model the professionals' knowledge and learning goals are acknowledged and confirmed.

The findings are in line with Dieckmann's (2009) arguments that the norms and traditions of organisations influence the attitudes, anticipations, skills and knowledge of the participants and the instructors. However, following Schatzki (2002), we also want to argue that the expert model and the collegial model of enacting the introduction are guided by different teleoaffective structures.. These teleoaffective structures are also materialised through the sociomaterial set-up and arrangements of the simulation centres. Previous research by us and others (e.g. Nyström et al., 2016a; Nyström et al., 2016b; Titzler, Swenty \& Hoehn, 2012) emphasises how the material arrangements of different locations, spaces as well as time allocated for an exercise are entangled with the emerging practices. In the expert model, the material set-up as a traditional classroom reinforces the instructor's role as the primary knower. In the primus inter pares model, the different material set-up of a round table prefigures the teaching practice of a seminar. These material and social arrangements of the simulation centres make certain activities of a practice more likely to happen than others.

So far, we have discussed how different teleoaffective structures can shape how the introduction phase of a simulation training is enacted. A central aspect of CPD is to reflect upon what was learned and relate the learning outcome to the professional practice (Boud \& Hager, 2012). In simulation research, the reflective phase, i.e. the debriefing stage is similarly emphasised as crucial for enabling professional learning (e.g. Rudolph et al., 2006; Motola et al., 2013). Dieckmann et al. (2012) argue that the participants need to reflect upon their experiences in order to reconstruct and transform their experiences from simulation into practice. Interestingly, we did not see the interconnections with different institutional traditions of teaching practice emerging clearly in the reflection phase. Instead, the teaching practice in the reflection phase echoed more clearly the teleoaffective structures of the simulation practice itself, and was enacted in the same way at both sites. This was particularly strong concerning the norms of how a debriefing should be enacted, and what steps to go through in what order (e.g. Jeffries, 2013).

The reflection practices at both sites were characterised by attunement to relatings between different entities in the simulation. These were relatings between the participant, simulated patient and the medical equipment and the performance of the team. The reflective practice emphasised describing individual doings as professional performances along with 
paying particular attention to the medical aspects of the simulation. These foci for reflection can be seen as reinforcing individual professional formation and performance rather than focusing on the formation and understanding of a collaborative practice.

However, the study shows instances of reflections of individual performance related to team performance, even if this seldom happened. In the performance of the team analysis, the instructor and the participants reflect upon the individual performance against the backdrop of the performance of the team and related to social and material conditions such as communication, taking actions and bodily positionings. These findings emphasise communication as an important aspect of interprofessional collaboration, which is also expressed in other studies (e.g. Thistlethwaite, 2012). However, in cases where there are reflections on how to take action, and the embodiment of professional bodies becomes a topic for reflection, interprofessional collaboration becomes more than communication. The focus on embodied knowings shifts the attunements from individuals' doings and sayings as well as medical aspects towards interprofessional bodily actions and understandings. A focus on these kinds of actions and interactions in practice may contribute to the understanding of how to facilitate reflection post-simulation that goes beyond the merely descriptive and evaluative questions and answers that may lack the potential to stimulate deep learning (Husebø et al. 2013). Practice based concepts such as body positionings and material arrangements could be used as alternative starting points for reflection on interprofessional collaboration.

In line with other studies (e.g. Dieckmann, 2009; Husebø et al., 2013), this study emphasises the importance of and the role of the instructor and his/her ability to facilitate deeper reflection and interprofessional learning. The findings show that the differences in pedagogical practices between the two sites as the professional development activity was introduced disappeared in the reflection phase of the simulation. A possible explanation of this could be that the common and widespread model of how to conduct a simulation (i.e. briefing, simulation and debriefing) acts on the practice in a normative sense. This normativity can be viewed as a teleoaffective structure of the simulation practice itself, which overrides the general and practical understanding of teaching and learning embedded in the institutional practices. If that is the case, there is a paradox in that the professional development emphasises learning the procedure of the simulation, but not the idea that the simulation was supposed to illustrate. The findings of this study hence support the suggestion in previous research on continuing professional development (e.g. Reich, Rooney \& Boud, 2015 ) that the attention has shifted from the purpose and outcome to the activity itself.

Luff and Heath (2012) point out that use of video as a means of data collection in simulation research is increasing but in qualitative research has not been subject to discussions on methodological concerns to the same extent as more traditional methods, such as interviews, fieldwork or focus groups. Typically, the methodological issues raised in relation to the use of video as a method of data collection have concerned issues of access to records, ethical issues and the possible effect of video-recording on the on-going activities. It has been argued that usage of empirical data from video-recordings will enable the researchers to trace and discuss the practice of simulation in embodied and material terms (Hopwood, 2014). Video can make available multi-modal analyses, which can provide very detailed accounts of visual interaction and talk in the material environment. The large amount and richness of obtained data can at the same time be problematic and difficult to integrate with certain kinds of analytic framework. Luff and Heath (2012) also suggest that problems can also arise regarding how to codify and categorise video data, or how to select and analyse fragments of data. In this study, the research team developed a purposeful way of analysing data collaboratively, to ensure richness of the professional perspectives applied, as well as 
trustworthiness and transparency regarding how the foci and criteria for the analysis were used.

A critical reflection on this study is that the methodology was limited to what could be captured with observations and documents. Additional interviews with the professionals might have enriched the understandings further.

\section{Conclusions}

Activities for continuing professional learning for healthcare professionals are suggested to be necessary to be able to work in contemporary health care. This paper focuses on CPD of interprofessional collaboration and how these activities are arranged with simulation-based team training. The findings show that the professional development activity is enacted and interconnected with and governed by historical traditions of institutional teaching practices, as well as the normativity of simulation practices. Despite clear intentions of team and interprofessional training, other practices constrain and hinder the intended learning outcomes. The findings show that the outcomes of reflection of interprofessional scenariobased collaboration are vulnerable and dependent on how individual performances are related to team performance and material arrangements.

\section{References}

Berragan, L. 2011. “Simulation: an effective pedagogical approach for nursing?” Nurse Education Today 31 (7): 660-663.

Boeije, H. 2002. "A Purposeful Approach to the Constant Comparative Method in the Analysis of Qualitative Interviews.” Quality \& Quantity 36: 391-409.

Boud, D. \& Hager, P. 2012. "Re-thinking continuing professional development through changing metaphors and location in professional practices.” Studies in continuing education 34 (2): 17-30.

Bradbury, H., Kilminster, S., O’Rourke, R., \& Zukas, M. 2015. "Professionalism and practice: critical understandings of professional learning and education.” Studies in continuing education, 37 (2): 125-130.

Dickmann, P. 2009. "Simulation settings for learning in acute medical care.” In Using simulations for education, training and research, edited by P. Dieckmann, 40-138. Pabst Science Publishers; Lengerich.

Dieckmann, P., Molin Friis, S., Lippert, A., \& Østergaard, D. 2012. “Goals, success factors, and barriers for simulation-based learning: a qualitative interview study in health care”. Simulation \& Gaming 43 (5): 627-647.

Fanning, R., \& Gaba, D. 2007. "The role of debriefing in simulation-based education." Simulation in healthcare 2 (2): 115-125 
Fenwick, T., \& Abrandt Dahlgren, M. 2015. "Towards sociomaterial approaches in simulation-based education: lessons from complexity theory.” Medical Education, 49 (4), 359-367.

Fox, A., \& Reeves, S. 2015. "Interprofessional collaborative patient-centred care: a critical exploration of two related discourses.” Journal of interprofessional care 29 (2): 113-118.

Gherardi, S. 2009. "Knowing and learning in practice-based studies: an introduction. The Learning Organization.” 16 (5), 352-359.

Green, B., \& Hopwood, N. (Eds.) 2014. The Body in Professional Practice, Learning and Education: Body/Practice. Dordrecht: Springer.

Gough, S., Hellaby, M., Jones, N. \& MacKinnon, R. 2012. “A review of undergraduate interprofessional simulation-based education.” Collegian 19 (3): 153-171

Guile, D. 2014. Interprofessional working and learning: a conceptualization of their relationship and its implications for education. In Reconceptualising professional learning, Edited by T. Fenwick \& M. Nerland, 125-140. Routledge: London.

Heath, C., Hindmarsh, J, \& Luff, P. 2010. Video in qualitative research. Analysing Social interaction in Everyday Life. Los Angeles: SAGE.

Husebø, D., Dieckmann, P., Rystedt, H. Friberg, F. 2013. ”The relationship between facilitators' questions and the level of reflection in the post-simulation debriefing." Simulation in healthcare 8 (3): 135-142.

Hopwood, N. 2014. "Using video to trace the embodied and material in a study of health practice”. Qualitative research journal, 14 (2):197-211

Interprofessional Education Collaboration Expert Panel. 2011. Core competencies of interprofessional collaborative practice: report of an expert panel. Washington, D.C.: Interprofessional Education Collaborative.

Jeffries, P. 2013. Clinical Simulations in nursing education: advanced concepts, trends, and opportunities. New York: National league of nursing.

Kemmis, S. 2009. Understanding professional practice: A synoptic framework. In Understanding and researching professional practice, edited by B. Green, 19-38. Rotterdam: Sense Publishers.

Kemmis, S. \& Grootenboer, P. 2008. Situating Praxis in Practice: Practice Architectures and the Cultural, Social and Material Conditions for Practice. In S. Kemmis and T. J. Smith. (Eds.), Enabling Praxis: Challenges for Education (pp. 37-62). Rotterdam: Sense Publications

Luff, P. \& Heath, C. 2012, "Some 'technical challenges' of video analysis: social actions, objects, material realities and the problems of perspective." Qualitative Research, 12 (3): 255-279. 
Motola, I., Devine, L. A., Chung, H. S., Sullivan, J. E., \& Issenberg, S. B. 2013. "Simulation in healthcare education: A best evidence practical guide. AMEE Guide No. 82.” Medical Teacher 35 (10): e1511-e1530

McDermott, D. 2016. The prebriefing concept: A Delphi study of CHSE experts. Clinical simulation in nursing. 12: 219-227.

Nyström, S., Dahlberg, J., Hult, H. \& Abrandt Dahlgren, M. 2016a. "Enacting simulation: A sociomaterial perspective on students' interprofessional collaboration.” Journal of interprofessional care 30 (4): 441-447.

Nyström, S., Dahlberg, J., Edelbring, S., Hult, H., \& Abrandt Dahlgren, M. 2016b. "Debriefing practices in interprofessional simulation with students: A sociomaterial perspective.” BMC Medical education. 16: 148.

Reich, A., Rooney, D., \& Boud, D. 2015. "Dilemmas in continuing professional learning: learning inscribed in frameworks or elicited from practice.” Studies in continuing education 37 (3): 131-141.

Rooney, D., Hopwood, N., Boud, D., \& Kelly, M. 2015. “The Role of Simulation in Pedagogies of Higher Education for the Health Professions: Through a Practice-Based Lens.” Vocations and Learning, 8 (3): 269-285.

Schatzki, T. 2010. “Materiality and Social Life.” Nature and Culture, 5 (2): 123-149.

Schatzki, T. 2002. The site of the social: A philosophical account of the constitution of social life and change. University Park: Pennsylvania State University Press.

Titzer, J. L., Swenty, C. F., \& Hoehn, W. G. 2012. ”An Interprofessional Simulation Promoting Collaboration and Problem Solving among Nursing and Allied Health Professional Students.” Clinical Simulation Nursing. 8 (8): e325-33.

Thistlethwaite, J. 2012. "Interprofessional education: a review of context, learning and the research agenda.” Medical education 46: 58-70.

World Health Organization 2010. Framework for action on interprofessional education and Collaborative Practice. WHO; Geneva. 